\title{
Artificial stupidity
}

\author{
Richard Ennals ${ }^{1}$
}

Published online: 9 March 2016

(C) Springer-Verlag London 2016

In 1988 the Stockholm Conference "Culture, Language and Artificial Intelligence" included a special track of sessions with the theme "Artificial Stupidity". This included a discussion of the American Strategic Defense Initiative, "Star Wars: A Modern Version of Shakespeare's Tempest?" Many years later, we can appreciate the appropriateness of this title, suggested by conference organiser Bo Göranzon.

Pulitzer Prize-winning author Richard Rhodes reconstructed the summit meetings held between President Reagan and General Secretary Gorbachev in autumn 1986, using detailed personal interviews with participants, and a wealth of new documentation. Written primarily for an American audience, the book focuses on the USA and Soviet Union, and summit meetings between Reagan and Gorbachev.

At the centre of the discussion is the ludicrous but terrifying Strategic Defense Initiative (SDI, or "Star Wars"). It would now seem, according to Rhodes, that only Ronald Reagan believed in it. He thought it would be possible to build an impregnable "peace shield" against ballistic missile attack, thus making all nuclear weapons obsolete. The emperor had no clothes. His courtiers, such as Richard Perle, Deputy Secretary of Defense, treated him like a backward child and manipulated him shamelessly, ensuring that his adherence to SDI was at the expense of arms reduction.

Rhodes has more sympathy for the position of the Soviet Union when addressing arms reduction, than the

Richard Ennals

richard.ennals@gmail.com

1 Department of Skill and Technology, Linnaeus University, Växjö, Sweden duplicitous posturing of the Reagan administration. He dismisses the idea that SDI won the Cold War for the USA, as we had been asked to believe.

There is an important question. If everyone at the summits thought SDI was nonsense, except for Reagan, how was it able to wreck the arms reduction process? Why was this sceptical consensus not disclosed sooner? Are we wrong to believe in modern scientific processes of rational decision making? What is really going on? Where does that leave scientists? How can we deal with power? What happened to whistle blowing? Are there implications for education in science and technology?

"Arsenals of Folly" makes it clear that both sides agreed in 1986 that nuclear weapons are massively dangerous, and could never be used. Each side made selective use of figures to justify maintaining and building up their own nuclear stockpiles for defensive reasons. This meant using money that could have been devoted to civil purposes, such as health and education.

This continues. There are currently people in the UK who favour the replacement of the American-controlled Trident missile system, housed in submarines. The public debate has yet to be conducted. Nuclear weapons, including Trident, are enormously expensive. How can such use of public funds be justified? How can informed public debate be encouraged? Austerity is made much deeper by such expenditure.

SDI was based on the false prospectus that technology could provide impregnable defence against missile attack. We continue to make unreasonable assumptions about what technology can do, as if this could free us from the responsibility to make sensible decisions. The educational challenge is formidable. 
"Arsenals of Folly" does not deal with wider collateral damage to allies such as the UK. Across NATO and the Warsaw Pact, rational debate was effectively suspended. Why did the politicians stay silent? Should we revise our histories of the period? One day there may be an authoritative book about the impact of this nonsense on NATO and Warsaw Pact partners, where governments were not allowed to tell the truth. This was why the UK government asked for help from academics and the peace movement, as ministers and civil servants were unable to work through usual channels. On a windswept Vauxhall Bridge in late summer 1985, I was asked to "talk to my friends".

My own book "Star Wars: A Question of Initiative", intended to be published by Wiley in 1986 to coincide with the Reykjavik Summit, tried to cast light on this. In particular, I explored implications for UK research in advanced IT. The first edition was withdrawn and pulped when publishers Wiley suddenly worried about my revelations about the real reasons for the resignations of Defence Secretary Michael Heseltine and Industry Secretary Leon Brittan in January 1986, and my disclosures about the apprehending of Pentagon agent Clarence Robinson and a Czech agent. It was not possible to find a UK government minister who had both been briefed on SDI and supported it. In the USA, behind the scenes there was deep concern.

If I had been reaching basically the same conclusions about SDI in 1985-1986, as "Arsenals of Folly" in 2007, why did it take so long for such a critique to appear from a respected historian? Perhaps the legendary Ronald Reagan had to be dead and gone. At the summits, he relied on cue cards written by his advisers, and hoped he had had been prepared for the right conversations. Subsequent Presidents George and George W Bush defended the Reagan legacy.

Have we learned? It is interesting to read recent histories of technology and defence policy, and to see evident efforts to airbrush SDI out of the picture. Like the loss of the war in Vietnam, SDI is something that many Americans would rather forget. Many technology journalists, enthusiasts for artificial intelligence, have never heard of SDI and artificial stupidity. In so-called democracies, how can such travesties continue? Why do we continue to fall for preposterous claims by snake oil salesmen? Do we have a responsibility to make it less likely that our contemporaries and students will be taken in? I think so.

Curmudgeon Corner Curmudgeon Corner is a short opinionated column on trends in technology, arts, science and society, commenting on issues of concern to the research community and wider society. Whilst the drive for super-human intelligence promotes potential benefits to wider society, it also raises deep concerns of existential risk, thereby highlighting the need for an ongoing conversation between technology and society. At the core of Curmudgeon concern is the question: What is it to be human in the age of the AI machine? -Editor.

\section{Reference}

Rhodes R (2007) Arsenals of folly: the making of the nuclear arms race. Simon and Schuster, New York. ISBN 978-1-84737-118-8 